\title{
Clinical efficacy and cost-effectiveness of bespoke compared with over-the-counter foot orthoses for plantar heel pain
}

\author{
Katie Ring ${ }^{*}$, Simon Otter \\ From Society of Chiropodists and Podiatrists Annual Conference 2010 \\ Bournemouth, UK. 21-23 October 2010
}

\begin{abstract}
Objectives and relationship to conference themes Plantar heel pain is a common foot complaint often managed with orthoses; however, bespoke foot orthoses can be time-consuming and expensive to manufacture. Therefore we aimed to compare the clinical efficacy and cost-effectiveness of bespoke foot orthoses and prefabricated foot orthoses for heel pain.
\end{abstract}

\section{Presentation topic}

A total of 67 patients with plantar heel pain were recruited for this study; if, following initial assessment, foot orthoses were indicated patients were randomised to receive either bespoke orthoses or pre-fabricated semi-rigid orthoses (Powerstep). Clinical efficacy was assessed at 4 and 8 weeks using the Manchester foot pain and disability questionnaire and cost-effectiveness was determined by analysing the material, manufacture and labour costs.

\section{Participant outcomes}

At baseline there were no appreciable differences in the two groups of patients in demographic or clinical parameters. At 4 and 8 weeks post intervention both types of orthoses had significantly reduced pain and disability ( $\mathrm{p}<0.0001)$. The Powerstep insoles cost $£ 17.45$ (19.36 Euros) in total where as the bespoke orthoses were considerably more expensive at $£ 26.86$ (29.80 Euros) to provide.

\section{Relevance}

For most patients with plantar heel pain pre-fabricated semi-rigid insoles such as the Powerstep devices used in

University of Brighton, Brighton, UK

(c) 2010 Ring and Otter; licensee BioMed Central Ltd. This is an open access article distributed under the terms of the Creative Commons Attribution License (http://creativecommons.org/licenses/by/2.0), which permits unrestricted use, distribution, and reproduction in any medium, provided the original work is properly cited. this trial provide equal benefit to bespoke, casted foot orthoses, but are considerably cheaper.

Published: 20 December 2010

doi:10.1186/1757-1146-3-S1-O22

Cite this article as: Ring and Otter: Clinical efficacy and cost-

effectiveness of bespoke compared with over-the-counter foot orthoses for plantar heel pain. Journal of Foot and Ankle Research 2010 3(Suppl 1): 022.

Submit your next manuscript to BioMed Central and take full advantage of:

- Convenient online submission

- Thorough peer review

- No space constraints or color figure charges

- Immediate publication on acceptance

- Inclusion in PubMed, CAS, Scopus and Google Scholar

- Research which is freely available for redistribution 